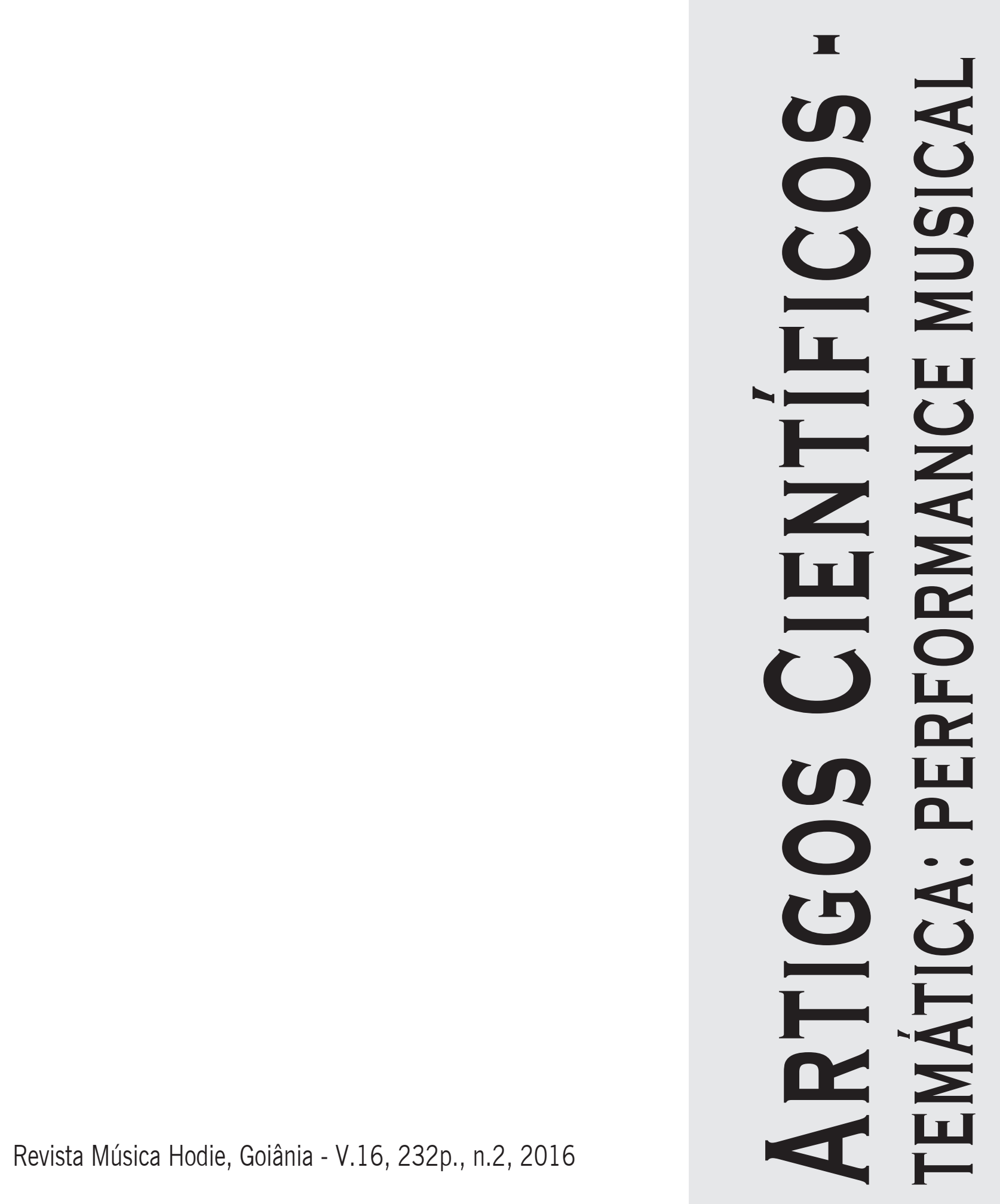




\title{
Memórias Líquidas para Waterphone solo e Live Loops: criação, performance e transtextualidade
}

\author{
Luís Bittencourt (Universidade de Aveiro, Aveiro, Portugal)
}

bittencourt.mail@gmail.com

\begin{abstract}
Resumo: Memórias líquidas, para waterphone solo e live loops, é uma obra musical resultante de uma pesquisa prévia sobre as possibilidades sonoras do waterphone e suas combinações com universos musicais distintos como a dança sul-americana Chacarera e o bombo legüero. O objetivo deste artigo é discutir a criação e performance de Memórias Líquidas como processos transtextuais, utilizando como método a análise da obra através do conceito de transtextualidade de Gérard Genette. Neste projeto a performance, composição e investigação surgem como atividades interdependentes e complementares, e o processo de tradução ocupa um lugar central para a compreensão da obra.

Palavras-chave: composição musical; performance musical; transtextualidade; waterphone; chacarera e bombo legüero; música contemporânea.
\end{abstract}

Liquid Memories for solo waterphone and live loops: creation, performance and transtextuality

Abstract: Liquid Memories, for solo waterphone and live loops, is a musical work resulting from a previous research on the sonic possibilities of the waterphone and its combination with different musical universes such as the SouthAmerican dance Chacarera and the legüero drum. This article aims to discuss the creation and performance of Liquid Memories as transtextual processes, using as method for the analysis the Gérard Genette's transtextual theory. In this project the performance, composition and research emerge as interdependent and complementary activities, and it positions translation as a central process for the understanding of the work.

Keywords: music composition; music performance; transtextuality; waterphone; chacarera and bombo legüero; contemporary music.

Memorias liquidas para solo waterphone y loops en vivo: creación, performance y transtextualidad

Resumen: Memorias liquidas, para solo waterphone y loops en vivo, es una obra musical que resulta de una investigación basada en las posibilidades sonoras del waterphone y sus combinaciones con diferentes universos musicales como la danza sudamericana Chacarera y el bombo legüero. El propósito de este artículo es discutir la creación y performance musical de Memorias Líquidas como procesos transtextuales, utilizando como método de análisis el concepto de transtextualidad de Gérard Genette. En este proyecto la performance, la composición y la investigación, surgen como actividades interdependientes y complementarias. El proceso de traducción desempeña un papel fundamental en la comprensión de la obra.

Palabras clave: composición musical; performance musical; transtextualidad; waterphone; chacarera y bombo legüero; la música contemporánea.

"Memórias líquidas"1 é uma peça musical para waterphone solo e live loops que compus entre 2013 e 2014. O ímpeto para criá-la surgiu a partir de minha necessidade, enquanto performer, de dispor de obras solo para o waterphone e, como investigador, de explorar e ampliar o potencial sonoro do instrumento e suas técnicas de execução. Apesar do waterphone ser utilizado em obras orquestrais e de música de câmara, o seu repertório solista é praticamente inexistente, assim como a investigação a seu respeito.

A obra baseia-se no ritmo da dança sul-americana conhecida como Chacarera e em um dos seus instrumentos característicos, o bombo legüero. ${ }^{2}$ A ideia de combinar estes elementos com o waterphone surgiu de forma bastante natural. O instrumento tem estado no centro de minhas atividades desde o ano de 2009, e a chacarera, assim como o bombo legüero, fazem parte de minhas memórias acerca das músicas e sonoridades ouvidas em minha terra natal durante a infância e, por consequência, contribuíram para compor minha identidade cultural. A combinação de elementos tão distintos se apresentou como uma potencialidade latente para a criação de uma obra musical.

Este estudo tem como objetivo descrever o processo de composição da obra Memórias líquidas, para waterphone solo e live loops, e analisá-lo como um processo transtextual, 
através da teoria homónima desenvolvida por Gérard Genette em sua obra "Palimpsestos: a literatura de segunda mão". Inicialmente serão abordadas as relações de teorias como hibridismo, intertextualidade e transtextualidade com a composição musical. A seguir, um breve panorama sobre o waterphone e suas principais características. Posteriormente é descrito o processo de criação da obra e características dos seus elementos constituintes, como a chacarera e o bombo legüero, a criação de sonoridades no waterphone e o uso de recursos eletrônicos. Por fim, são realizadas reflexões analíticas acerca do processo de composição e suas relações com o conceito de transtextualidade.

\section{Hibridismo, intertextualidade e transtextualidade: intersecções com a composição musical}

É comum encontrarmos obras musicais que incorporam material de outras pré-existentes e esta é uma prática possivelmente tão antiga quanto a própria música (BURKHOLDER 2001; MECONI, 2004). Especialmente na música sacra dos séculos XV e XVI, a primeira etapa da composição de uma nova obra era a escolha de uma melodia, geralmente de canções populares monofônicas ou eventualmente motetos e peças instrumentais, para utilizar como estrutura base (cantus firmus) de toda uma arquitetura composicional subsequente (STEIB, 1995, p. 5). O empréstimo de materiais ocupa um lugar central no desenvolvimento da polifonia e da música ocidental (MECONI, 2004; STEIB, 1996) e ainda permanece como uma prática bastante explorada por diversos compositores na atualidade.

Na música do século XX, o empréstimo musical ou, utilizando o termo, mais preciso, de Born e Hesmondhalgh (2000), a "apropriação” de música pré-existente evidenciou relações entre música e cultura, como fez Charles Ives, que constantemente citou marchas e hinos em suas composições para exaltar o sentimento nacionalista, ou Béla Bartók, compositor e pesquisador da música tradicional de diversos povos, cuja a obra, repleta de elementos de diferentes culturas, tinha como objetivo semear a "fraternidade das nações" (GRIFFITHS, 1987, p. 53).

Nesta primeira metade do século XXI, uma época em que o mundo é "atravessado por 'autoestradas' de informação” (BAUMAN, 2007, p. 11), o acesso a culturas distantes é mais facilitado e "à medida em que áreas diferentes do globo são postas em conexão umas com as outras, ondas de transformação social atingem virtualmente toda a superfície da terra” (Giddens apud Hall, 1992, p. 15). Nesse contexto de constantes transformações sociais, a composição musical passa a dialogar intimamente com termos como "multiculturalismo" (GRISWOLD, 1994; NICHOLLS, 1996; HESMONDHALGH, 2000), "intertextualidade" (HATTEN, 1985; ALLEN, 2000; HESMONDHALGH 2000; KLEIN, 2005; BARBOSA e BARRENECHEA, 2003; KAWAMOTO, 2006) e "hibridismo" ou "hibridização" (PAPASTERGIADIS, 2005; BORN e HESMONDHALGH, 2000; PIEDADE, 2011, 2013; RIOS FILHO, 2010). Em relação a este último termo, Mikhail Bakhtin (1895-1975), estudioso do assunto sobretudo na área da linguística, assim o define:

O que é uma hibridização? É uma mistura de duas linguagens sociais dentro dos limites de um único enunciado, um encontro, dentro da área de um enunciado, entre duas consciências linguísticas diferentes, separadas uma da outra por uma época, por diferenciação social ou por algum outro fator. (BAKHTIN, 1981, p. 58, minha tradução) ${ }^{3}$

É particularmente interessante para este estudo observar o pensamento de Boaventura de Sousa Santos sobre hibridização. Santos (2002, p. 355-356) vê a hibridização como uma "atuação sobre os próprios limites", um processo no qual os limites são desestabiliza- 
dos mas não necessariamente superados, e que, assim, tornam-se vulneráveis e abertos a novas combinações e interpenetrações com outros limites (Idem, p. 356).

Nesta perspectiva híbrida merece atenção o conceito de intertextualidade proposto por Julia Kristeva. A partir dos estudos de Saussure, Barthes e Bakhtin sobre a teoria literária, Kristeva adota o termo intertextualidade para propor que "todo texto se constrói como um mosaico de citações, todo texto é absorção e transformação de um outro texto” (KRISTEVA, 1974, p. 68). No entanto, a intertextualidade não se refere a "uma adição confusa e misteriosa de influências, mas sim pelo trabalho de transformação e assimilação de vários textos operados por um texto central que mantém a liderança do sentido" (KRISTEVA apud BALOGH, 2002, p. 28). SOUZA (2008, p. 322) chama a atenção para o fato de que uma criação textual que usa ou se baseia, conscientemente, em textos de outros autores, transformando e recriando-os, perdeu a conotação pejorativa e que processos como imitação, plágio, influência, etc., têm de ser reconsiderados frente ao conceito de intertextualidade.

Em uma abordagem mais profunda do conceito de intertextualidade, Gérard Genette desenvolve o conceito de transtextualidade para definir "tudo o que posiciona o texto em uma relação, seja óbvia ou oculta, com outros textos” (1997, p. 1). Genette descreve um conjunto de cinco relações transtextuais, entre as quais, a intertextualidade, e também paratextualidade, metatextualidade, arquitextualidade e hipertextualidade. A primeira destas relações, intertextualidade, se refere a uma "relação de co-presença entre dois ou vários textos, isto é, essencialmente, e o mais freqüentemente, como presença efetiva de um texto em outro" (GENETTE, 2006, p. 8). A citação, o plágio ou a alusão são alguns exemplos de práticas intertextuais. A paratextualidade diz respeito às relações do texto com seu paratexto, que é o conjunto de elementos adicionais ao texto em si como título, subtítulo, intertítulos, prefácios, posfácios, advertências, prólogos, etc.

Em um terceiro nível está metatextualidade, que é a relação "que une um texto a outro texto do qual ele fala, sem necessariamente citá-lo (convocá-lo), até mesmo, em último caso, sem nomeá-lo" (Idem, p. 11). A metatextualidade é mais frequentemente entendida como "comentário" (Ibid.) e "todos os críticos literários, ao longo dos séculos, têm produzido metatextos sem o saber” (GENETTE, 1992, p. 82). O quarto tipo de relação transtextual é a hipertextualidade, que se refere a "toda relação que une um texto B (que chamarei hipertexto) a um texto anterior A (que, naturalmente, chamarei hipotexto) do qual ele brota, de uma forma que não é a do comentário" (GENETTE, 2005, p. 12). A relação hipertextual pode ocorrer através de processos como transformação ou imitação e estes, por sua vez, derivam em procedimentos específicos como a paródia, pastiche, transposição, tradução, entre outros. Finalmente, a arquitextualidade é, de acordo com Genette, o tipo mais abstrato e mais implícito. É definida por uma relação silenciosa, que implica apenas uma menção paratextual ou infratitular como as classificações taxonômicas que acompanham as obras (se é um romance, poema, narrativa, etc.).

Tabela 1: Tipos de transtextualidade e suas características. Elaborado a partir dos conceitos de Genette (2005).

\begin{tabular}{|l|l|l|}
\hline $\begin{array}{c}\text { Tipos de } \\
\text { transtextualidade }\end{array}$ & \multicolumn{1}{|c|}{ Características } & Procedimentos \\
\hline intertextualidade & $\begin{array}{l}\text { relação de copresença entre dois ou vários textos; presença efetiva de } \\
\text { um texto em outro }\end{array}$ & citação, plágio, alusão, entre outros. \\
\hline paratextualidade & $\begin{array}{l}\text { relações do texto com seu paratexto (conjunto de elementos adicionais } \\
\text { ao texto em si) }\end{array}$ & $\begin{array}{l}\text { título, subtítulo, intertítulos, prefácios, } \\
\text { posfácios, advertências, prólogos, etc. }\end{array}$ \\
\hline metatextualidade & $\begin{array}{l}\text { relação que une um texto a outro texto do qual ele fala, sem necessaria- } \\
\text { mente citá-lo ou convocá-lo, até mesmo, em último caso, sem nomeá-lo }\end{array}$ & comtários \\
\hline hipertextualidade & $\begin{array}{l}\text { toda relação que une um texto B (hipertexto) a um texto anterior A (hi- } \\
\text { potexto) do qual ele brota, de uma forma que não é a do comentário }\end{array}$ & $\begin{array}{l}\text { trantormação ou imitação (paródia, pasti- } \\
\text { chensposição, tradução, entre outros) }\end{array}$ \\
\hline arquitextualidade & $\begin{array}{l}\text { relação silenciosa, que implica apenas uma menção paratextual ou in- } \\
\text { fratitular como as classificações taxonômicas que acompanham as obras }\end{array}$ & $\begin{array}{l}\text { arquitetar a forma da obra (se é um ro- } \\
\text { mance, poema, narrativa, etc.) }\end{array}$ \\
\hline
\end{tabular}




\section{Waterphone}

Por utilizar uma instrumentação bastante peculiar, não há como descrever o processo de criação de Memórias Líquidas sem antes abordar o waterphone, um instrumento que utiliza as propriedades da água para ampliar suas possibilidades sonoras e como um componente essencial para a produção do seu timbre característico. Sua origem data do ano de 1976 e está associada ao artista plástico norte-americano Richard Waters (1935-2013), que inventou e construiu o instrumento sob o nome da companhia Multi-Media na cidade de Sebastopol, California (EUA) (DAVIES, 1984). O modelo de waterphone criado por Waters é construído em aço inoxidável e bronze e consiste em um corpo ressonador oco, com o formato de bacia (na parte inferior) e o topo na forma de cúpula, em que está inserido um tubo cilíndrico. À volta da cúpula estão conectadas cerca de 25 a 35 pequenas varas, dispostas quase verticalmente, que são usualmente friccionadas através de um arco. O número e tamanho das varas pode variar dependendo do modelo do instrumento.

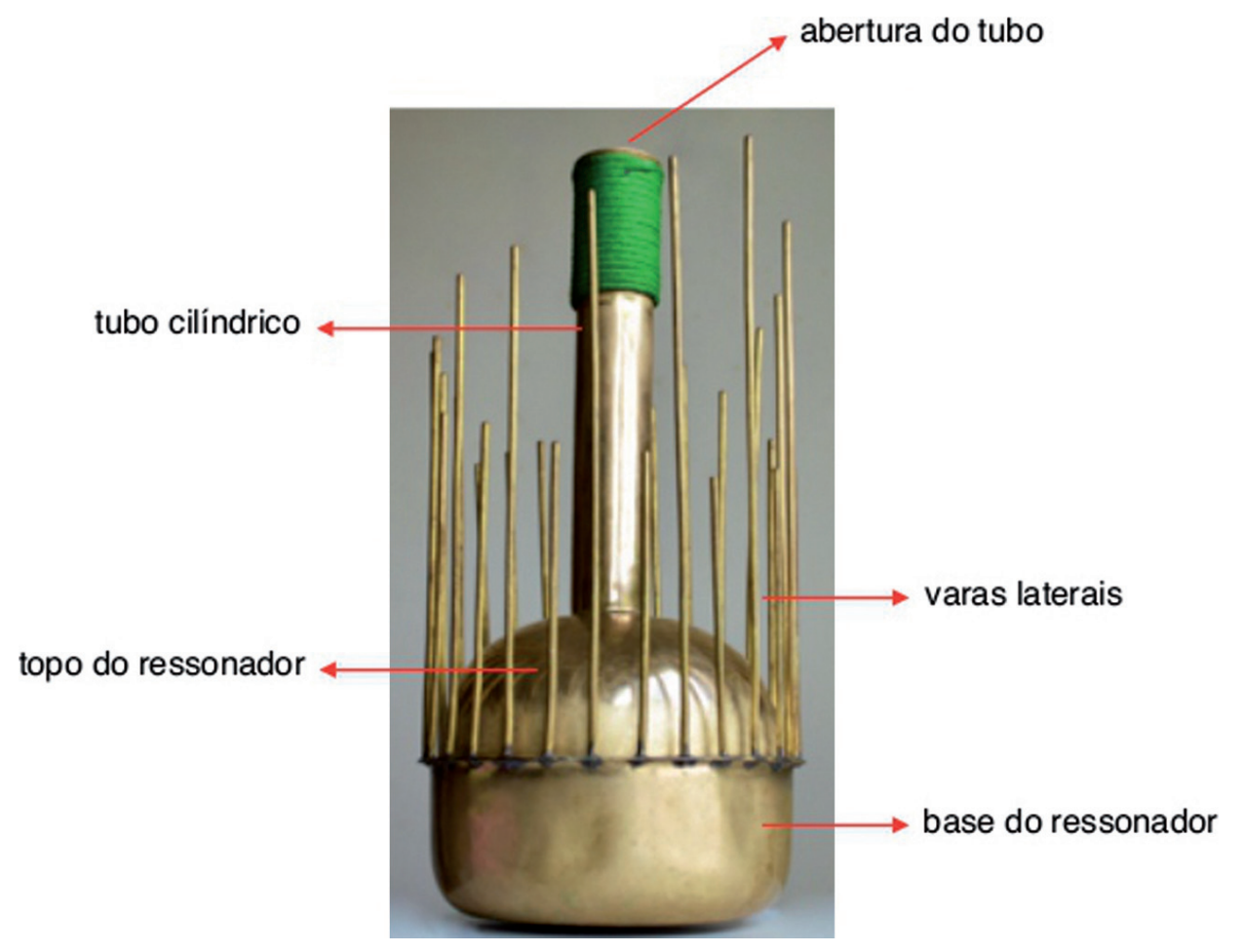

Figura 1: Waterphone.

O waterphone não possui uma afinação padronizada. A afinação das varas, dispostas ao redor do corpo do ressonador, varia de acordo com cada instrumento pois mesmo dois instrumentos de um mesmo modelo podem possuir afinações diferentes. É encontrado com afinações que incluem desde intervalos do sistema temperado até variações de micro-tons ou quartos de tom. A principal característica sonora do waterphone é que o interior do instrumento pode ser preenchido com uma pequena quantidade de água de modo que, quando o instrumento é ligeiramente movimentado, após o golpe, são produzidos variados glissandos ascendentes e descendentes.

Atualmente, o waterphone é fabricado por outros luthiers e difundido sob diferentes nomenclaturas e formatos. Alguns dos nomes utilizados para referir diferentes modelos do instrumento são ocean harp, aquasonic e aquaphone. As principais diferenças observadas entre os modelos atuais disponíveis são o tipo de material utilizado (bronze, aço inoxidável, latão, etc.), o formato do corpo do instrumento (mais ou menos espesso, achatado 
ou cilíndrico, etc.) e a disposição das varas ao redor do tubo, que podem ser organizadas gradualmente ou aleatoriamente. Na composição e performance de Memórias líquidas, foram utilizados dois modelos distintos do instrumento: o Aquasonic waterphone (Figura 2) e Ocean harp waterphone (Figura 3).

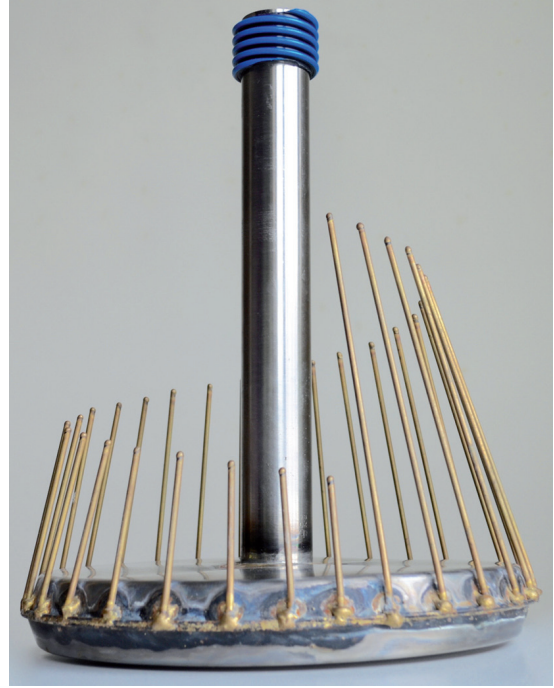

Figura 2: The Aquasonic waterphone.

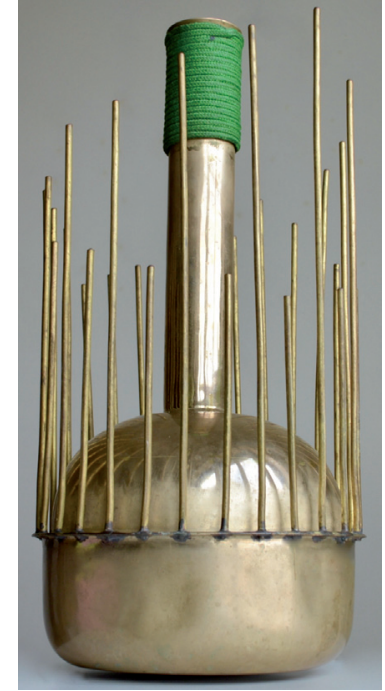

Figura 3: Ocean Harp waterphone.

\section{Chacarera e bombo legüero}

A criação de Memórias líquidas surgiu a partir de minha necessidade de dispor de uma obra solo para waterphone e de investigar as formas de produzir som no instrumento e ampliar o seu escopo de técnicas de execução. Em meu ponto de vista, a criação artística (nesse caso, a composição musical) mostrou-se como uma forma de suprir minha necessidade enquanto performer e também como um catalisador para o processo de pesquisa. Como "matéria-prima” para a composição utilizei o ritmo da dança sul-americana Chacarera e um dos seus instrumentos característicos, o bombo legüero (Figura 4).

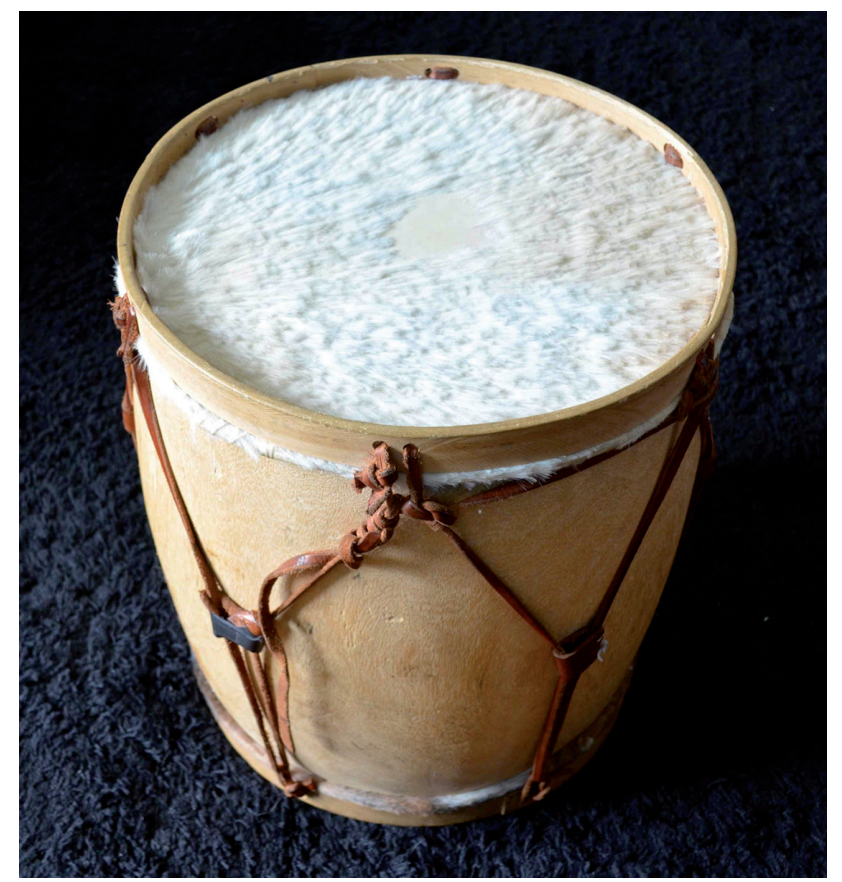

Figura 4: Bombo legüero. 
A partir do ritmo básico da chacarera, executado no bombo legüero, procurei "traduzir" para o waterphone, não apenas a célula rítmica desta dança, mas sobretudo parâmetros específicos como o timbre, fraseado e articulação característicos do bombo legüero. Minha intenção foi abordar o waterphone tal como um tambor para revelar as suas potencialidades percussivas que são, usualmente, esquecidas ou pouco exploradas, uma vez que sua forma de execução mais difundida é através do uso de um arco (a qual confere um caráter mais harmônico e melódico ao instrumento).

Através de uma pesquisa documental (bibliográfica, discográfica e videográfica) pude constatar quão escassos são os estudos e informações precisas acerca destes elementos, especialmente sobre o bombo legüero. De origem incerta, seu surgimento é associado aos tambores trazidos pelos escravos africanos e à "caixa de guerra", 4 um tambor precursor da caixa-clara que era utilizada pelos colonizadores europeus (ARETZ, 1952). Por ser um tambor utilizado por negros, índios e mestiços, era inicialmente também chamado de bombo indio ou bombo criollo de orquestra. Posteriormente, difundiu-se a ideia de que o instrumento, devido à sua grande amplitude sonora, podia ser ouvido a léguas ${ }^{5}$ de distância - e daí o seu o nome legüero (BUGALLO, 1993, p. 39).

A chacarera é originalmente uma dança e música tradicional da região noroeste da Argentina, mais especificamente, da Província de Santiago del Estero. Apesar desta localidade ser considerada o referencial geográfico do seu surgimento e disseminação, a chacarera é também encontrada em quase toda a Argentina e suas reminiscências podem também ser observadas em ritmos e danças de outros países e regiões da América Latina, sobretudo no sul do Brasil, algumas vezes sob a forma de outras nomenclaturas e variações. ${ }^{6}$

O surgimento da chacarera é incerto e a ausência de documentos que descrevam suas primeiras manifestações dificultam descrever, precisamente, a sua origem. Considerada como uma dança e música de origem criolla, a chacarera é resultado da miscigenação cultural entre os missionários europeus, os nativos indígenas e os escravos vindos da África (ABECASSIS, 2004; LAMARQUE, 2010). Adolfo Ábalos, músico argentino responsável por inovações na interpretação pianística de obras de caráter popular e referência do folclore argentino, descreve como essa confluência de etnias deu origem à chacareira:

\footnotetext{
Imaginemos: antes de ser descoberta, na América estavam os incas com suas flautas e um ritmo musical de dois tempos; quando vieram os espanhóis, trouxeram escravos de Angola e estes construíram no Peru o que hoje conhecemos como bombo legüero, e também incorporaram seu ritmo de três tempos. A partir disto seguiu um intercâmbio musical, em segunda geração, dos incas, espanhóis e negros. E quando os espanhóis desceram e fundaram Santiago del Estero, começou a surgir a chacarera, esta música misteriosa (ÁBALOS apud LAMARQUE, 2010, p. 21).
}

A música da chacarera é normalmente executada por pequenos grupos instrumentais que incluem a guitarra, voz e bombo legüero, podendo também incluir eventualmente outros instrumentos como acordeão, violino e harpa. Uma de suas características é a proeminência de polirritmias decorrente da utilização simultânea de métricas ternária e binária composta como, por exemplo, a sobreposição de um acompanhamento rítmico em compasso $3 / 4$ e uma melodia executada em 6/8. No entanto há muitas controvérsias e discussões ${ }^{7}$ teóricas acerca de qual fórmula de compasso a chacarera deve ser escrita ou se a mesma realmente exige a utilização de fórmulas de compasso distintas para melodia e ritmo, entre outras questões. 
Outra característica rítmica singular da chacarera é a acentuação dos tempos do compasso. Em um compasso 3/4 a acentuação usual incide sobre o primeiro tempo sendo que os restantes são considerados tempos fracos. Já a acentuação da chacarera em um compasso em $3 / 4$, porém, ocorre no segundo e terceiro tempos conforme explica Vitillo Ábalos, músico do grupo folclórico argentino Los Hermanos Ábalos: "O primeiro tempo deve ser considerado fraco e o segundo e terceiro deverão ser considerados tempos fortes, sendo o terceiro mais forte e apoiado que o segundo" (Ábalos apud Degregorio, s/d, s/p). ${ }^{8}$ Assim, a acentuação da chacarera é completamente contrária ao padrão europeu de acentuações métricas para compassos 3/4 e que, de acordo com Ábalos, concede à chacarera o caráter peculiar da música criolla: "O ritmo de da chacarera deve ser escrito no pentagrama em compasso 3/4 e o que diferencia nossa música criolla do resto da música do mundo é a acentuação do segundo e terceiro tempo" (Ibid.).

A execução da chacarera no bombo legüero visa produzir, basicamente, duas alturas sonoras contrastantes: uma grave, obtida através da percussão da pele do tambor, e outra aguda, produzida pela percussão do aro do instrumento. No excerto abaixo o som agudo está representado pelas notas localizadas na parte superior da pauta, com a cabeça da nota em forma de "x"; os sons graves estão representados pelas notas inferiores da pauta, localizados no espaço correspondente à nota Fá3 escrita na clave de Sol.

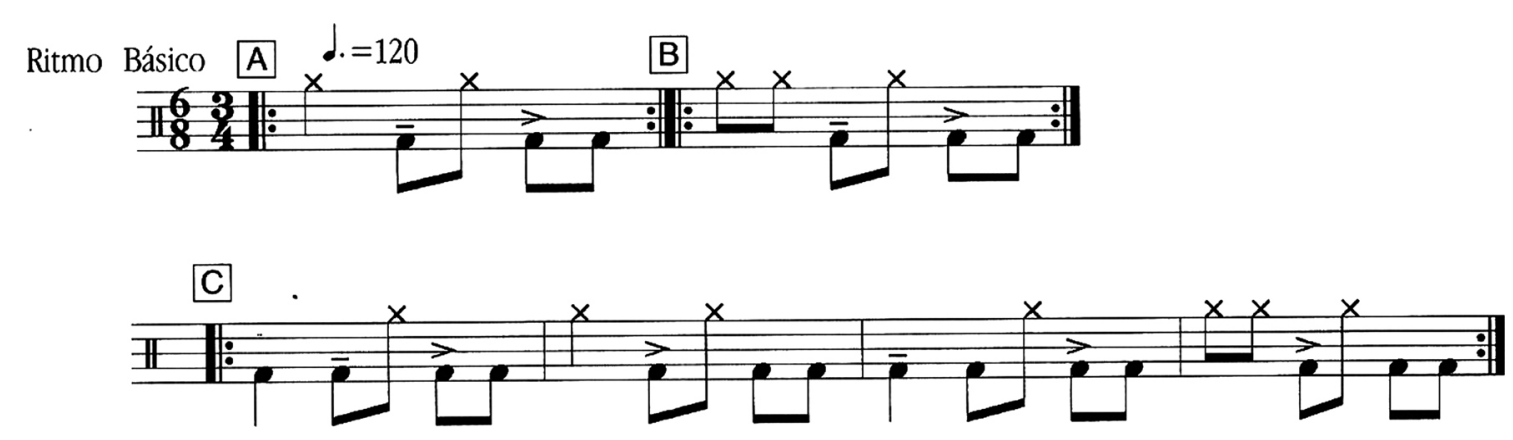

Exemplo 1: Ritmo básico da chacarera e variações. ${ }^{9}$

Assim, parte do processo criativo fundiu-se com a pesquisa sonoridades no waterphone que fossem correspondentes àquelas produzidas pelo bombo legüero na chacarera. Isso implicou na reflexão sobre novas abordagens do instrumento e no desenvolvimento de técnicas estendidas de execução instrumental, bem como possibilidades de orquestração e arranjo no waterphone. Para a sonoridade grave do legüero, por exemplo, procurei explorar a percussão do tubo do waterphone, com a mão espalmada, de forma a obter um som grave semelhante ao som do bombo percutido na pele; para o som agudo do legüero, utilizei a percussão da parte lateral do corpo do waterphone com uma baqueta de metal (brush stick ou vassourinhas usadas pelos bateristas de jazz), produzindo uma sonoridade aguda e similar ao som dos golpes produzidos no aro do bombo.

\section{Criação e pesquisa: o estúdio como um laboratório}

A utilização de métodos centrados na prática como ferramenta de pesquisa, como creative practice as research (prática criativa como pesquisa) ou studio research (pesquisa no estúdio) desempenhou um papel fundamental para o processo de criação da obra e também para este estudo. Tais métodos são estratégias de investigação que visam produzir conhecimento sobre a prática, através da prática, e a partir da perspectiva do performer da 
ação em contexto (HASEMAN, 2006, p. 3). Esta abordagem está associada a um emergente terceiro paradigma de investigação, denominado por Haseman (2006) como "Performative Research”. Nesse sentido, o estúdio é, para as artes criativas como a música, um espaço de experimentações, criações e desenvolvimento e a sua existência se torna, para o artista, tão necessária quanto o laboratório é para o cientista (EDMONDS et al, 2005, p. 457). Esta visão é também partilhada por Gramelsberger em seu artigo "A laboratory view of art”:

Em relação a um ponto de vista laboratorial da arte, os estudos em estúdio poderiam ajudar a ganhar mais conhecimento sobre as perspectivas múltiplas e coletivas do conhecimento criado por artistas individuais. E podem conseguir isso através da abordagem à investigação de forma coletiva e em múltiplas perspectivas. (GRAMELSBERGER, 2013, p. 108)

O uso da pesquisa em estúdio como método tem muito a ver com o conceito de "sistemas experimentais"10 de Hans-Jörg Rheinberger, que também foi útil como suporte teórico nesta etapa. Rheinberger decreve os sistemas experimentais como "arranjos que nos permitem criar singularidades espaço-temporais cognitivas” (RHEINBERGER apud ASSIS, 2013, p. 157) ou ainda como "espaços exteriorizados da imaginação" (RHEINBERGER, 2013, p. 210). Acrescenta ainda que a estrutura de um sistema experimental é também acompanhada de um "espírito experimental" em que a interação do experimentador com o seu material é fulcral: "se não se está imerso, ou até soterrado pelo material, não há experimentação criativa” (Idem, p. 198). Também merece atenção a concepção de Rheinberger acerca da importância do estúdio para o desenvolvimento do trabalho do artista:

O estúdio de um artista não é apenas um espaço estético, geralmente é também um espaço de trabalho epistêmico que contém um grande investimento intelectual e material, investimentos que tendem a desaparecer no produto. Mas, para o artista, o estúdio é um aspecto integral de seu trabalho, sem o qual ele ou ela provavelmente não seria motivado para realizar esse trabalho. (Idem, p. 216)

Assim como afirma Rheinberger, o estúdio é um aspecto integral e motivador do trabalho do artista e a criação de parte do material sonoro de Memórias líquidas, bem como aspectos práticos da pesquisa das possibilidades sonoras do waterphone, foram permeados por este método. A pesquisa em estúdio promoveu um "cenário" de coesão entre as necessidades do performer e do investigador e foi essencial, do ponto de vista epistêmico e artístico, para concretizar os objetivos almejados.

\section{Exploração Sonora}

De forma geral, o material sonoro de Memórias líquidas pode ser organizado em dois grandes grupos sonoros, os quais chamarei de percussivo ${ }^{11}$ e harmônico. ${ }^{12}$ De forma a tornar a leitura do texto mais fluente, estes grupos serão referidos, de agora em diante, pelas letras $\mathrm{P}$ e $\mathrm{H}$, respectivamente. $\mathrm{O}$ grupo $\mathrm{P}$ é composto por diversos sons que são explorados em diferentes partes do instrumento, através de baquetas e gestos distintos. Conforme mencionado anteriormente, minha intenção foi "traduzir" a sonoridade do bombo legüero ${ }^{13}$ para o waterphone e pesquisar as suas possibilidades enquanto instrumento rítmico. No grupo $\mathrm{P}$ estão cinco padrões rítmicos diferentes que são executados separadamente, em sequência, e depois sobrepostos através de loops para criar uma textura percussiva única e complexa. Estes padrões estão exemplificados no Exemplo 2: 


\section{RHYTHMIC LAYERS}

LAYER (1)

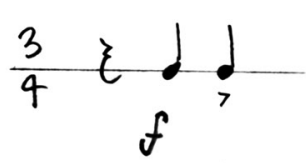

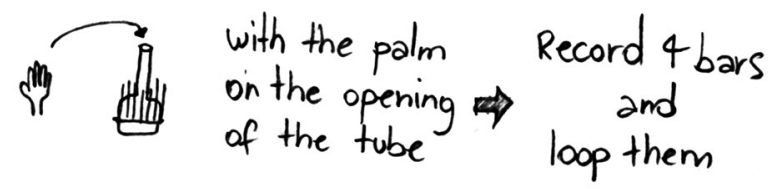

LAYER (2)

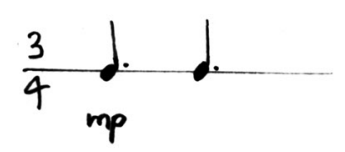<smiles>C[Si]1C=[Si]C1</smiles>

with broshes

in the side of the waterphone loop them

LAYER (3)

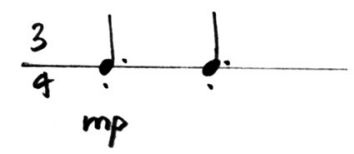<smiles>C=Cc1ccccc1</smiles>

scrape the metal Record 4 bars
rods with brushes loop them
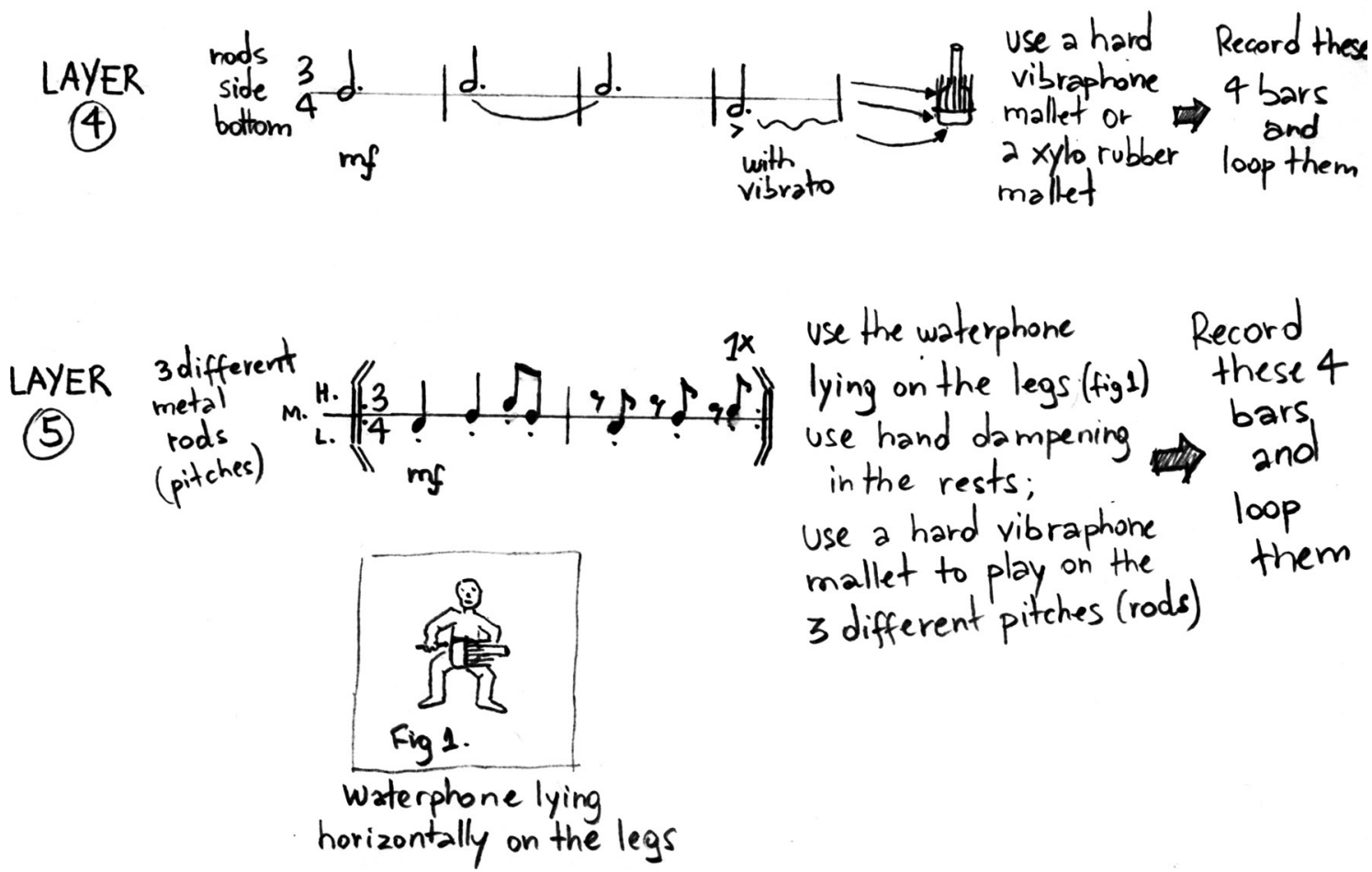

Exemplo 2: camadas rítmicas que compõem o Grupo P.

Algumas das técnicas de execução utilizadas no grupo $\mathrm{P}$ foram criadas especialmente para a peça, por exemplo, a percussão do instrumento através das mãos, mallets ${ }^{14} \mathrm{e}$ brushes $^{15}$, uso de abafamentos (hand dampening), entre outras. Também uma nova forma de segurar o instrumento foi desenvolvida para realizar alguns propósitos musicais desejados. Na sua forma de execução usual, o instrumentista utiliza uma das mãos para segurar o waterphone enquanto a outra mão executa os toques/golpes para produzir som, que pode ser através de um arco, baqueta, dedos, etc. (Figura 5). 


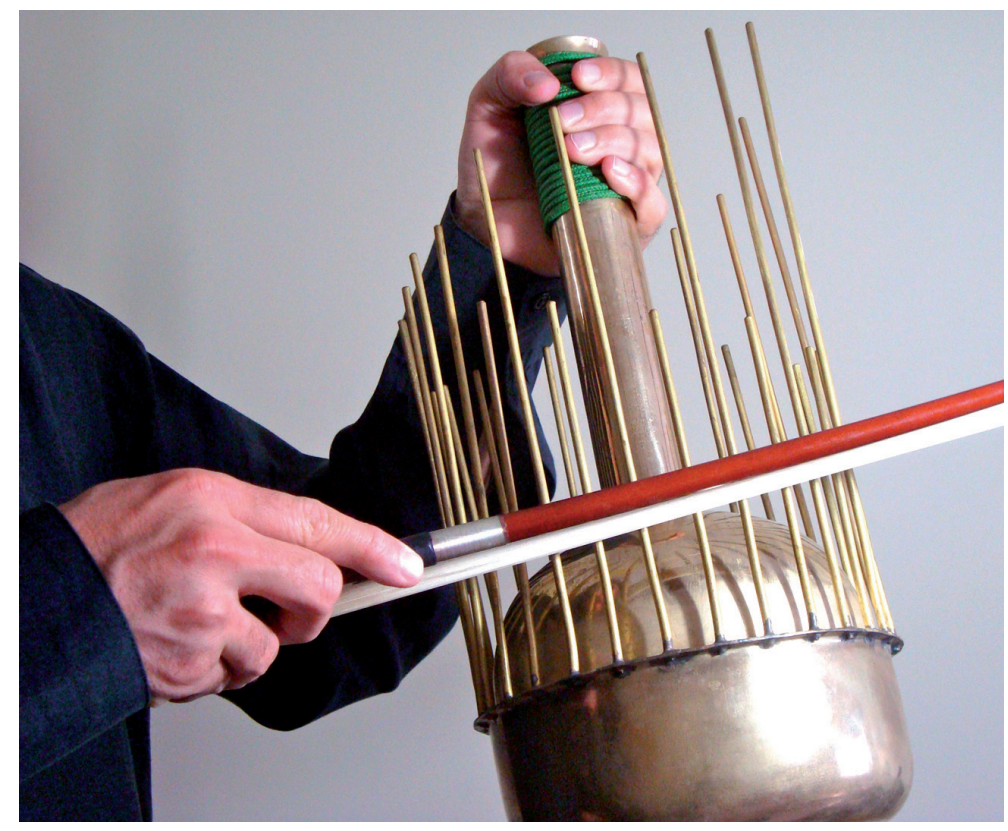

Figura 5: forma de executar o waterphone com o uso de um arco.

Assim, apenas uma das mãos do instrumentista está, efetivamente, executando o waterphone, o que torna limitada a performance de conteúdos musicais complexos. Esta limitação acabou por estimular o uso alternativo do instrumento apoiado sobre o colo do músico que, sentado, poderá utilizar ambas as mãos durante a execução (Figura 6).

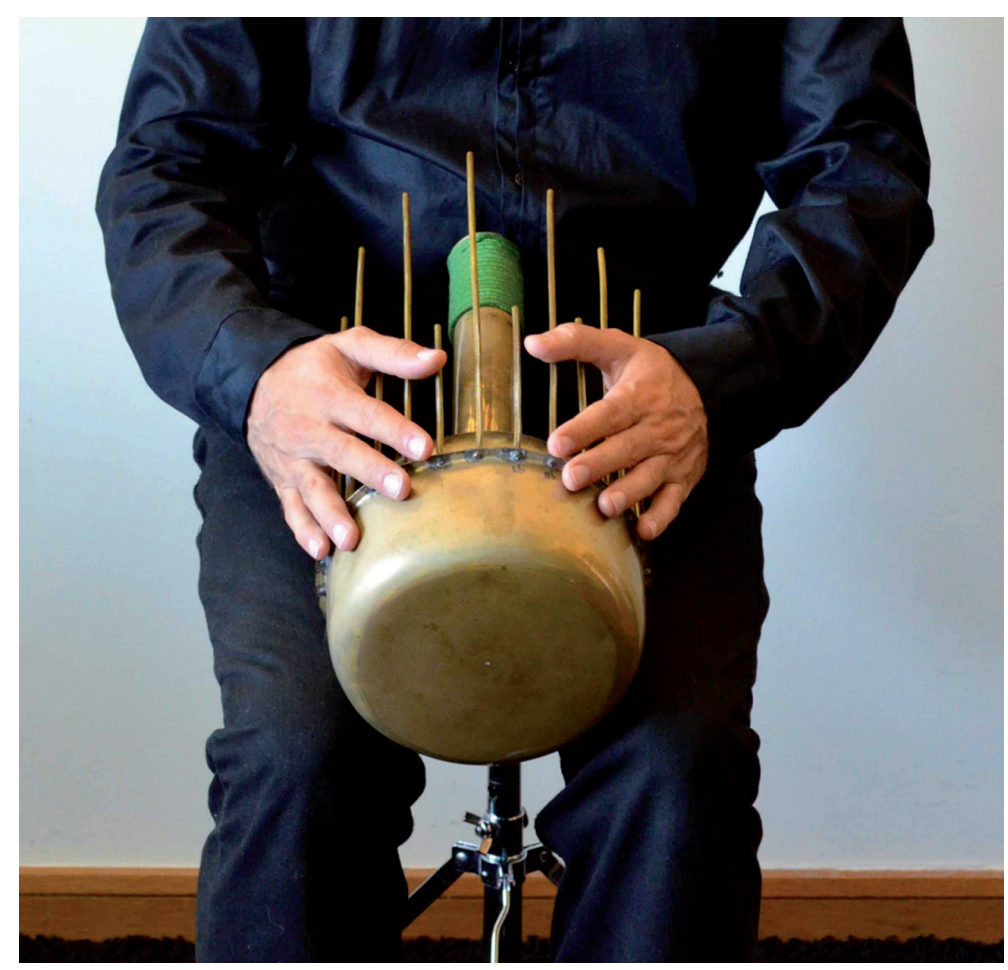

Figura 6: Execução do waterphone apoiado sobre o colo do instrumentista.

Esta maneira de executar o waterphone possui semelhanças com aquela utilizada em alguns membranofones (djembe, bongôs, etc.) e permite percutir o instrumento de várias formas, explorando ainda mais o seu potencial rítmico. Naturalmente, esta forma de execução também possui suas limitações na produção de determinadas sonoridades (como, por exemplo, o uso do arco nas varas, vibrato); no entanto, ela foi adequada para concretizar alguns das ideias musicais presentes em Memórias líquidas. 
O grupo H é composto por sons de diferentes alturas (pitches) que são produzidos nas varas do instrumento através do uso de um arco e técnicas adaptadas dos instrumentos de corda friccionada. A criação deste grupo teve como propósito obter uma textura sonora contrastante com a textura percussiva do grupo P, uma espécie de "bloco sonoro" harmônico em que predominam alturas definidas e distintas. É composto por uma única célula rítmica, executada em 5 diferentes alturas separadamente e em sequência, e que são sobrepostas através do looper (Exemplo 3). O resultado sonoro é um cluster executado em uníssono rítmico, com uma textura harmônica e contrastante com a textura percussiva do grupo P.

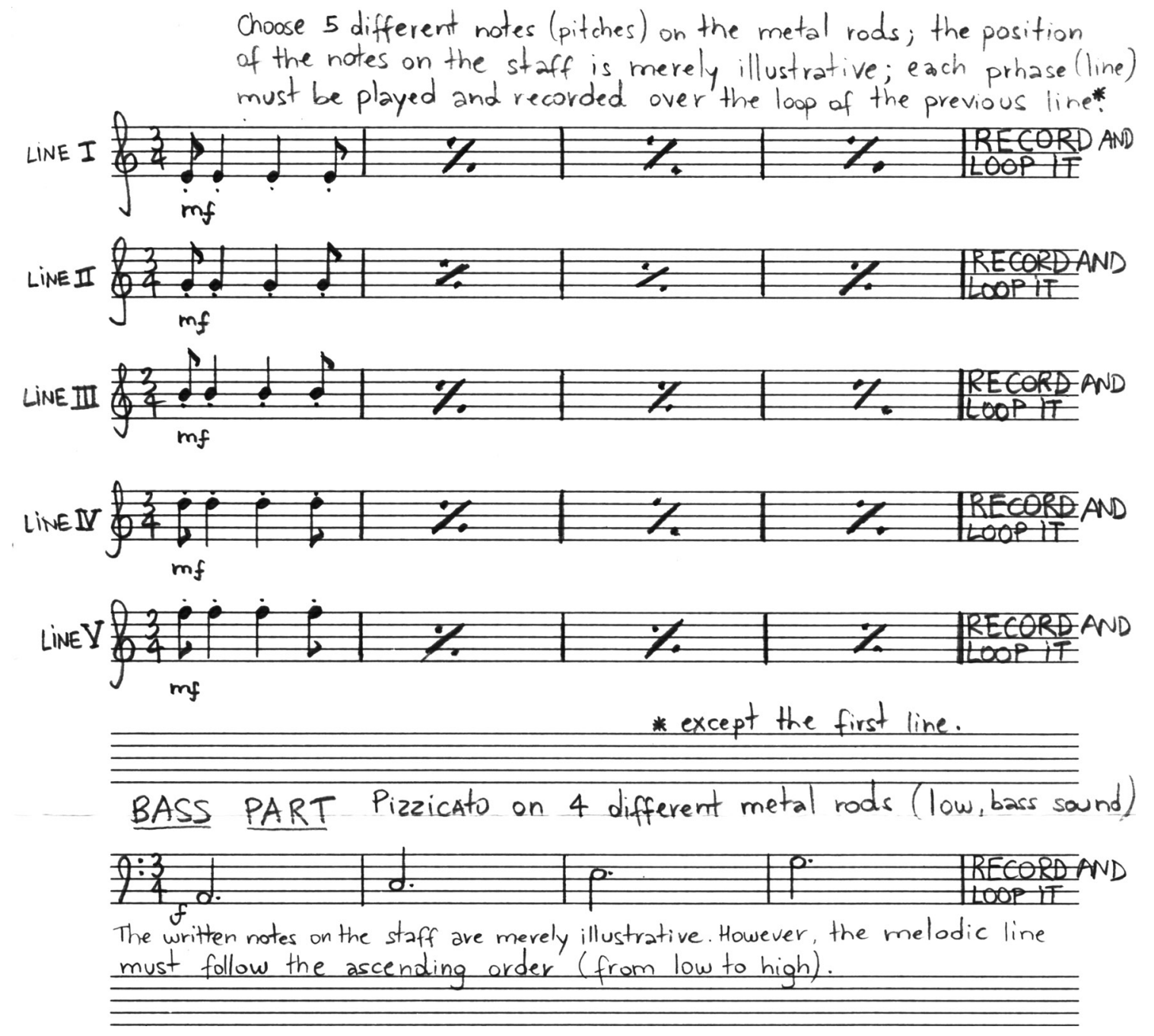

Exemplo 3: Camadas melódicas que compõem o Grupo $\mathrm{H}$.

A criação dos sons do grupo $\mathrm{H}$ foi permeada por sessões em estúdio com o waterphone e também pela pesquisa de técnicas de execução dos instrumentos de corda friccionada que, posteriormente, foram adaptadas para o waterphone. Nesta pesquisa, tive a oportunidade de entrevistar o contrabaixista António Aguiar, instrumentista do Remix Ensemble, grupo dedicado à performance do repertório contemporâneo e baseado na Casa da Música do Porto, Portugal. Além de ser um especialista em técnicas de arco frequentemente utilizadas no repertório dos séculos XX e XXI, Aguiar já executou partes escritas para waterphone em ensaios e concertos do Remix Ensemble. A partir de informações obtidas nesta entrevista e nas minhas experimentações com o instrumento, adaptei e desenvolvi algumas das técnicas que são utilizadas em Memórias líquidas. Essas técnicas incluem o spiccato, harmônicos artificiais, tremolo, ricochet e o pzicatto. 


\section{Estruturação e recursos eletrônicos}

De acordo com o ímpeto inicial de demonstrar a diversidade sonora do waterphone, procurei criar variações da célula rítmica da chacarera que foram orquestradas com sonoridades específicas investigadas. Estas variações foram distribuídas em 11 camadas (layers) distintas e, por exigirem diferentes técnicas de execução, logo ficou claro que não seria possível realizá-las, simultaneamente, em uma performance solo da obra. A solução adotada foi o uso de dispositivos eletrônicos, respectivamente os pedais de efeitos Boss RC-30 Loop Station e Electro Harmonix Freeze Sound Retainer. O primeiro funciona como um gravador digital para reprodução ao vivo (loops) de diferentes "camadas sonoras" (sound layers) em simultâneo ou separadamente. Esse dispositivo possibilitou a performance solo de partes musicais complexas que, do contrário, necessitariam de mais de um instrumentista para executá-las.

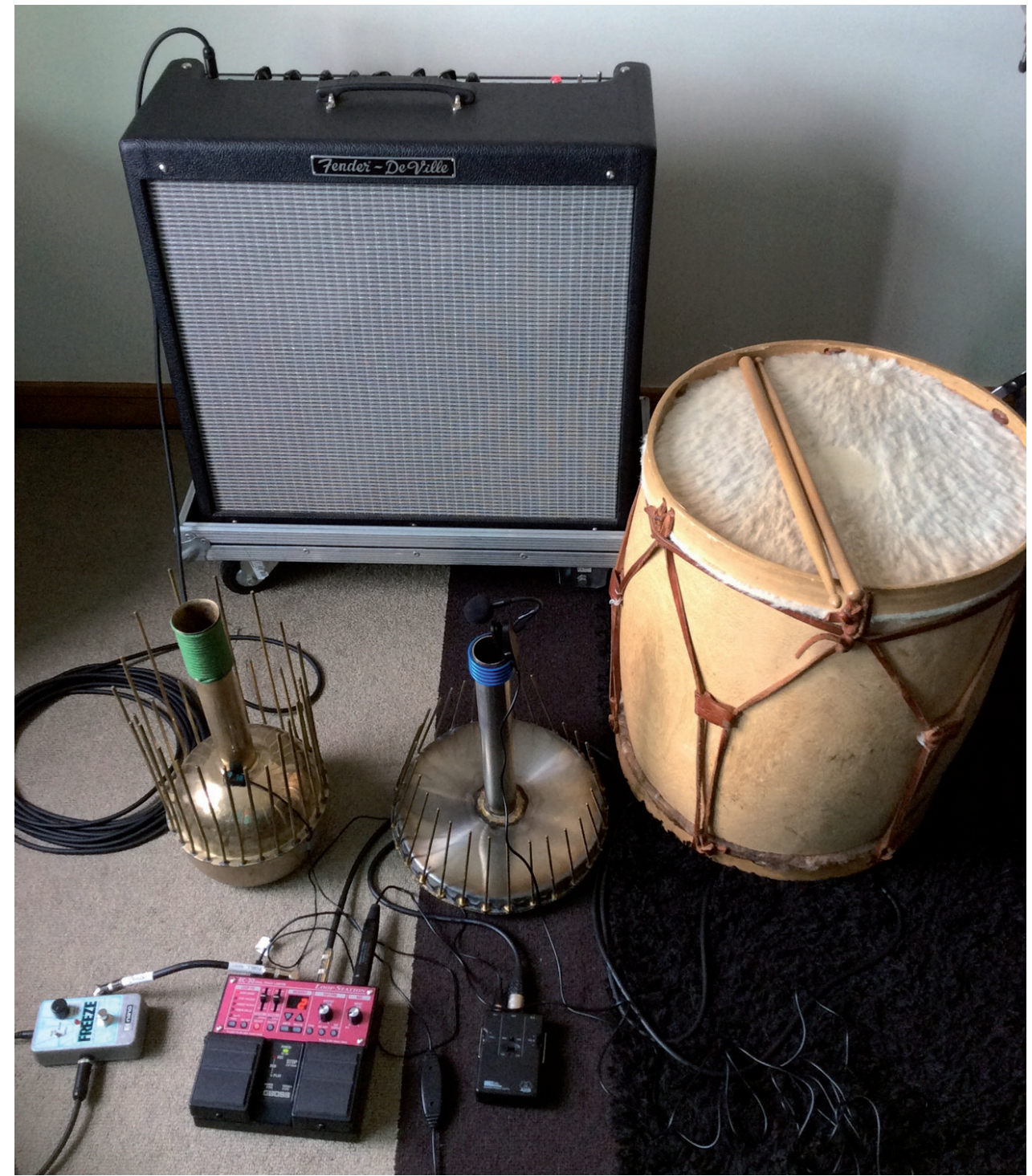

Figura 7: Conjunto de instrumentos utilizados em Memórias líquidas.

O Electro Harmonix Freeze atua como uma espécie de pedal de sustentação de um piano, com a diferença de que através deste é possível "congelar" o som produzido, sem qualquer diminuição da intensidade sonora (decay), por um tempo determinado de acordo com o desejo do músico. Através deste dispositivo foi possível combinar elementos sônicos distintos para a criação de novas possibilidades e texturas sonoras para a composição. 
De uma forma geral, tanto o Electro Harmonix Freeze quanto o Boss RC-30 Loop Station trouxeram soluções para a performance de ideias musicais concebidas previamente e, sobretudo, também estimularam a criação de outras novas e, assim, forneceram novas direções criativas para a obra.

\section{Reflexões analíticas}

A obra Memórias líquidas, para waterphone solo e live loops, tem sua gênese relacionada com necessidades pessoais de performance e pesquisa. Tais necessidades suscitaram uma terceira exigência (composição) e, ainda que todas estas atividades sejam distintas, elas foram complementares e essenciais, de forma que cada atividade informou e foi informada pela outra. Em outras palavras, a necessidade de dispor de obras solo para waterphone estimularam a criação de uma nova obra para o instrumento e as exigências intrínsecas ao processo criativo imprimiram a necessidade de investigar aspectos específicos do instrumento que talvez só tenham vindo à tona a partir da visão do artista (que, nesse caso em particular, é a fusão da visão do compositor e também do performer). Por outro lado, e simultaneamente, as descobertas e resultados prévios da investigação ofereceram direções para a composição musical, estimulando a criação através de um conhecimento sólido sobre as possibilidades e impossibilidades do instrumento. Nesse sentido, não seria correto tentar dissociar ou isolar as componentes artística e teórica pois estas foram cruciais para os resultados.

O conceito de transtextualidade de Genette pode ser utilizado como referencial teórico para a análise de aspectos específicos da obra. Ao transpormos este conceito à música, a partitura musical pode também ser encarada como um texto, um "espaço multidimensional, intertextual, constituído pela absorção e transformação de vários outros textos" (ABDO, 2000, p. 18). Muitos pesquisadores ${ }^{16}$ têm se dedicado aos estudos da intertextualidade como ferramenta de análise da música moderna e contemporânea, cujos processos composicionais "são permeados por relações intertextuais" (CERVO, 2015, p. 5).

A criação do material sonoro da obra, por exemplo, pode ser analisada através do conceito de hipertextualidade e um dos seus procedimentos específicos, a tradução. Conforme fora mencionado anteriormente, a ideia de hipertextualidade implica um texto A (hipotexto), que serve de base para a criação de um texto B (hipertexto). De acordo com Genette, o hipertexto é um texto que deriva de um processo de transformação formal e /ou temática (GENETTE apud LACASSE, 2003, p. 495). A transformação hipertextual pode realizada através de diferentes práticas. Para Genette, a transposição é a mais importante destas práticas e a tradução, que consiste em transportar um texto de uma língua para outra, é a sua forma mais evidente e difundida (GENETTE, 2005, p. 29).

Assim, a partir do ritmo básico da dança sul-americana chacarera, executado no bombo legüero, procurei traduzir para o waterphone, não apenas os ritmos desta dança, mas sobretudo parâmetros específicos como o timbre, fraseado e articulação característicos do bombo legüero na chacarera. Em uma analogia com a linguagem, procurei fazer com que o "idioma” da chacarera, bem como o "vocabulário" do bombo legüero, fossem expressados através do "sotaque" do waterphone. Sob a ótica da teoria de Genette, a obra Memórias líquidas torna-se um hipertexto que, ao mesmo tempo que preserva determinadas características de seus hipotextos constituintes, também revela algo novo.

O próprio título escolhido, Memórias líquidas, está imerso em relações paratextuais: o termo "memórias" está relacionado com o texto musical da chacarera que faz parte de minhas memórias acerca das canções populares de minha terra natal, o estado do Rio Gran- 
de do Sul (Brasil), e ouvidas durante minha infância e adolescência. Um exemplo nesse sentido é a canção "Veterano", ${ }^{17}$ de autoria de Leopoldo Rassier, baseada no ritmo da chacarera e em que o bombo legüero apresenta um papel bastante relevante. O termo "líquidas", por sua vez, relaciona-se com o texto sonoro do waterphone (que é também líquido por utilizar água na produção do seu timbre característico) e também com a obra de Zygmunt Bauman e seus textos sobre a liquidez na sociedade contemporânea, em que identidades globais se chocam com identidades locais, desmantelando fronteiras e fazendo com que não haja "terra nem povo desconhecidos, muito menos incognoscíveis” (BAUMAN, 2007, p. 11). Nesta perspectiva, Memórias líquidas promove a dissolução das fronteiras que separam a música erudita contemporânea da música regional gaúcha, bem como a fusão das identidades sonoras do waterphone e do bombo legüero.

O uso de dispositivos eletrônicos foi um fator essencial para a criação e, principalmente, performance da obra. Apesar destes dispositivos desempenharem um papel secundário na produção sonora, se comparado ao papel exercido pelo instrumento solista (waterphone), esta ideia não é, de todo, a mais correta. Através da performance da obra foi possível perceber que tais dispositivos exigem destreza técnica e domínio de conhecimentos específicos que tornam imprescindível o estudo meticuloso de como executá-los. Nesse sentido, estes não devem ser encarados como apenas dispositivos, mas sim, como instrumentos auxiliares. E em uma perspectiva hipertextual, estes dispositivos possibilitam que a "linguagem” ou texto da música eletrônica seja incorporado à "linguagem” acústica para, assim, criar um novo texto.

Memórias líquidas é também um esforço para demonstrar o potencial solista do waterphone na esperança de despertar o interesse de percussionistas pelo instrumento e, principalmente, compositores, para a criação de mais obras e ampliação do seu repertório. Por possuir trechos de improvisação e oferecer, até certo ponto, espaço para criar, a obra também abre espaço para que novas técnicas de execução do waterphone possam surgir futuramente, bem como novas pesquisas sobre o instrumento e suas possibilidades.

\section{Notas}

1 A estreia absoluta ocorreu a 21 de Fevereiro de 2014 no Departamento de Comunicação e Arte da Universidade de Aveiro, Portugal, e foi também estreada no Reino Unido no dia 13 de Março de 2014, em Leeds, Inglaterra. Pode ser ouvida no link https://soundcloud.com/luis-bittencourt-3/memorias-liquidas-for-solo-waterphone-and-live-loops.

2 “Tambor de duas peles com cerca de 15 polegadas de diâmetro, casco cilíndrico de madeira com cerca de 25 polegadas de altura, suspenso por corda ao ombro do instrumentista. É percutido por baquetas de madeira na pele e sistematicamente também no aro. É bastante comum na música Latino-Americana (Am. Do Sul e Central)”. (FRUNGILLO, 2002, p. 44).

3 Todas as traduções deste artigo foram realizadas pelo autor a partir da língua estrangeira original.

4 Membranofone percutido. Nome genérico dos tambores que possuem esteira ou bordões. Refere-se à caixa-clara, tarol ou tambor militar. (Frungillo, 2002, p. 56).

${ }_{5}$ Medida itinerária antiga cujo valor é variável segundo as épocas e os países, geralmente com valores entre os 4 e os 7 quilómetros. Pesquisado em Dicionário Priberam da Língua Portuguesa [online], 2008-2013, e acedido em http://www.priberam.pt/dlpo/l\%C3\%A9gua. Consultado em 24-10-2014.

6 Ver VEGA, 1944; ABECASSIS, 2004.

7 Para mais sobre esse assunto, ver ABECASSIS, Alberto. La chacarera bien mensurada. Río Cuarto, Argentina: Universidad Nacional de Río Cuarto, 2004; LAMARQUE, Carlos. Chacarera: Origens e transformações. Licenciatura em Música, CEART - Centro de Artes, Universidade do Estado de Santa Catarina (UDESC), 2010.

${ }^{8}$ Consultado em http://robinson-degregorio.blogspot.pt e acedido em 20/01/2015.

9 Consultado em http://bombolegueroypercusion.blogspot.pt/2007/03/bombo-legero_8794.html e acedido em 20/01/2015. 
${ }^{10}$ Por uma questão de espaço e objetividade ao tema, não será aqui discutido no que consiste os sistemas experimentais de Rheinberger. As suas quatro principais características estão descritas detalhadamente em seu ensaio "Experimental Systems: Entry Encyclopedia for the History of Life" (2004) disponível online em http://vlp. mpiwg-berlin.mpg.de/essays/data/enc19. Estas características são também discutidas resumidamente em Assis, Paulo. 2013. "Epistemic Complexity and Experimental Systems in Music Performance.” In Experimental Systems: Future Knowledge in Artistic Research, edited by Michael Schwab, 151-165. Leuven: Leuven University Press.

11 O grupo P pode ser ouvido a partir de 3’58” até 5’57” no link https://soundcloud.com/luis-bittencourt-3/memorias-liquidas-for-solo-waterphone-and-live-loops

12 O Grupo H pode ser ouvido a partir de 8'29" até 9'21” https://soundcloud.com/luis-bittencourt-3/memorias-liquidas-for-solo-waterphone-and-live-loops

${ }_{13}$ Pode-se ter uma ideia da sonoridade do instrumento através do link https://soundcloud.com/juanassabbi/bombo-leg-ero-mario-paz. Acedido em 23/04/2014.

14 Baquetas cujas as pontas são geralmente esféricas, cobertas por material que suaviza o contato com o instrumento (feltro, lã, pele, etc. ). Também conhecidas como "baqueta de teclado". (Frungillo, 2003, p. 200).

15 Conjunto de finos fios de arame, com o mesmo comprimento (em média 4,5”) amarrados ou fixados numa das extremidades de modo que na extremidade livre as pontas tendam a se afastar, tomando a forma de um ângulo que se abre como um leque ou abano. (Frungillo, 2002, p. 382 e 120). O termo é também utilizado para referir às "vassouras" que são usualmente utilizadas pelos bateristas de jazz.

${ }^{16}$ Kevin Korsyn, Michael Leslie Klein, Joseph N. Straus, Lúcia Barrenechea \& Cristina Gerling, Rodolfo Coelho de Souza, Edson Zampronha, Liduíno Pitombeira \& Flávio Lima.

17 Uma versão ao vivo da música pode ser ouvida no link https://www.youtube.com/watch?v=6C4pW03l4e0.

\section{Referências}

ABDO, Sandra Neves. Execução/Interpretação musical: uma abordagem filosófica. Per Musi Revista de Performance Musical da UFMG, Belo Horizonte, v. Jan-Jun, n. 1, p. 16-24, 2000.

ABECASIS, Alberto. La chacarera bien mensurada. Río Cuarto, Argentina: Universidad Nacional de Río Cuarto, 2004. 126p.

ALLEN, Graham. Intertextuality. London and New York: Routledge, 2006. 238p.

ARETZ, Isabel. El folklore musical argentino. Buenos Aires: Ricordi Americana, 1952. 271 p.

ASSIS, Paulo de. Epistemic Complexity and Experimental Systems in Music Performance. In: SCHWAB, Michael. (Ed.). Experimental Systems: Future Knowledge in Artistic Research. Leuven: Leuven University Press, 2013. p. 151-165.

BAKHTIN, Mikhail Mikhailovich. The dialogic imagination: Four essays by M.M. Bakhtin. Austin and London: University of Texas Press, 1981. 447p.

BALOGH, Anna Maria. A criação intertextual nos processos mediáticos. Significação: Revista de Cultura Audiovisual, São Paulo, v. 29, n. 18, p. 25-42, 2002.

BARBOSA, Lucas de Paula; BARRENECHEA, Lúcia. A intertextualidade musical como fenômeno. Per Musi - Revista de Performance Musical da UFMG, Belo Horizonte, v. jul-dez, n. 8, p. 125-136, 2003.

BAUMAN, Zygmunt. Tempos líquidos. Rio de Janeiro: Jorge Zahar Editor, 2007. 119p.

BORN, Georgina; HESMONDHALGH, David. Western Music and its Others: Difference, Representation, and Appropriation in Music. California: University of California Press, 2000. 360p.

BUGALLO, Rúben Pérez. Corrientes Musicales de Corrientes, Argentina. Latin American Music Review / Revista de Música Latinoamericana, v. 13, n. 1, p. 56-113, 1992.

. Catálogo ilustrado de instrumentos musicales argentinos. Buenos Aires: Ediciones del Sol, 1993. 168p. 
BURKHOLDER, J. Peter. Borrowing. In: SADIE, S. e TYRRELL, J. (Ed.). The New Grove Dictionary of Music and Musicians. London: McMillan Press, v. 4, 2001. p. 5-41.

CERVO, Dimitri. Influência, Intertextualidade e Pós-Modernismo no Concerto Grosso n. 1, de Alfred Schnittke, e na Série Brasil 2010 n. 6 - Concerto para Violino e Cordas, de Dimitri Cervo: Um estudo comparativo. Tese de pós-doutoramento, Escola de Música da Universidade Federal do Rio de Janeiro, 2015. Rio de Janeiro: UFRJ, 2015. 37 p.

EDMONDS, Ernest A. et al. The studio as laboratory: Combining creative practice and digital technology research. International Journal of Human-Computer Studies, v. 63, n. 4-5, p. 452-481, 2005.

FRUNGILlO, Mário D. Dicionário de percussão. São Paulo: Editora UNESP, 2003. 425 p.

GENETTE, Gérard. The architext: An introduction. Berkeley: University of California Press, 1992. $92 \mathrm{p}$. 1997. $490 \mathrm{p}$.

Palimpsests: Literature in the Second Degree. Lincoln: University of Nebraska Press,

. Palimpsestos: a literatura de segunda mão - extratos traduzidos do francês por Luciene Guimarães e Maria Antônia Ramos Coutinho. Belo Horizonte: Faculdade de Letras da UFMG, 2005. $48 \mathrm{p}$.

GRAMELSBERGER, Gabriele. A Laboratory View of Art. In: SCHWAB, Michael. (Ed.). Experimental Systems: Future Knowledge in Artistic Research. Leuven: Leuven University Press, 2013. p. 102-111.

GRIFFITHS, Paul. A música moderna: uma história concisa e ilustrada de Debussy a Boulez. Rio de Janeiro: Jorge Zahar, 1987. 206 p.

GRISWOLD, Harold. E. Multiculturalism, Music, and Information Highways. Music Educators Journal, v. 81, n. 3, p. 41-46, 1994.

HALL, Stuart. A identidade cultural na pós-modernidade. 4. ed. Rio de Janeiro: DP\&A Editora, 1997. 102p.

HASEMAN, Brad. A manifesto for performative research. Media International Australia, Incorporating Culture \& Policy, n. 118, p. 98-106, 2006.

HATTEN, Robert. S. The place of intertextuality in music studies. The American Journal of Semiotics, v. 3, n. 4, p. 69-82, 1985.

HESMONDHALGH, David. International Times: Fusions, Exoticisms, and Antiracism in Electronic Dance Music. In: BORN, Georgina e HESMONDHALGH, David. (Ed.). Western Music and its others: Difference, Representation and Appropriation in Music. Londres: University of California Press, 2000. p. 280-304.

KAWAMOTO, Akitsugu. Forms of Intertextuality: Keith Emerson's Development as a "Crossover" Musician. 2006. PhD. Department of Music, University of North Carolina at Chapel Hill, Chapel Hill.

KLEIN, Michael L. Intertextuality in Western Art Music. Bloomington: Indiana University Press, 2005. $200 \mathrm{p}$.

KRISTEVA, J. Introdução à semanálise. São Paulo: Ed. Perspectiva, 1974. 199 p.

LACASSE, S. Intertextuality as a tool for the analysis of popular music: Gérard Genette and the recorded palimpsest. In: GYDE, Alex e STAHL, Geoff. $12^{\circ}$ BIENNIAL IASPM INTERNATIONAL CONFERENCE - PRACTISING POPULAR MUSIC, 2003, Toronto. p. 494-503. 
LAMARQUE, Carlos. Chacarera: Origens e transformações. Licenciatura em Música. CEART - Centro de Artes, Universidade do Estado de Santa Catarina, 2010, Florianópolis: UDESC, 2010. 97 p.

MECONI, Honey. Introduction: Borrowing and early music. In: MECONI, H. (Ed.). Early musical borrowing. London and New York: Routledge, 2004. p. 1-4.

NICHOLLS, David. Transethnicism and the American Experimental Tradition. The Musical Quarterly, v. 80, n. 4, p. 569-594, 1996.

PAPASTERGIADIS, Nikos. Hybridity and ambivalence places and flows in contemporary art and Culture. Theory, Culture \& Society, v. 22, n. 4, p. 39-64, 2005.

PIEDADE, Acácio. Perseguindo fios da meada: pensamentos sobre hibridismo, musicalidade e tópicas. Per Musi - Revista de Performance Musical da UFMG, v. jan-jun, n. 23, p. 103-112, 2011.

. A teoria das tópicas ea musicalidade brasileira: reflexões sobre a retoricidade na música. El Oído Pensante, v. 1, n. 1, p. 1-23, 2013.

RHEINBERGER, Hans-Jörg. Forming and Being Informed. In: SCHWAB, Michael. (Ed.). Experimental Systems: Future Knowledge in Artistic Research. Leuven: Leuven University Press, 2013. p. 198-219.

RIOS FILHO, Paulo. A hibridação cultural como horizonte metodológico na criação de música contemporânea. Revista do Conservatório de Música da UFPel, v. 2010, n. 3, p. 27-57, 2010.

SANTOS, Boaventura de S. A crítica da razão indolente: contra o desperdício da experiência. 4. ed. São Paulo: Cortez Editora, 2002. 376 p.

SOUZA, E. A Intertextualidade nos processos de composição e interpretação da Seresta para Violão de José Alberto Kaplan. In: CONGRESSO NACIONAL DE PESQUISA E PÓS-GRADUAÇÃO EM MÚSICA, XVIII, 2008, Salvador, Bahia. p. 321-328.

STEIB, M. A Composer Looks at His Model: Polyphonic Borrowing in Masses from the Late Fifteenth Century. Tijdschrift van de Koninklijke Vereniging voor Nederlandse Muziekgeschiedenis, v. 46, n. 1, p. 5-41, 1996.

VEGA, Carlos. Panorama de la música popular argentina. Buenos Aires: Editora Losada, 1944. $353 \mathrm{p}$. 